Research Article

\title{
COVID-19 and Obesity: An Epidemiologic Analysis of the Brazilian Data
}

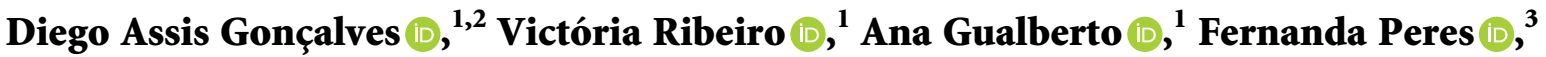 \\ Michaela Luconi $\mathbb{D}^{2}{ }^{2}$ and Jacy Gameiro $\mathbb{D D}^{1}$
}

${ }^{1}$ Department of Parasitology, Microbiology and Immunology, Federal University of Juiz de Fora, Juiz de Fora, Brazil

${ }^{2}$ Department of Experimental and Clinical Biomedical Sciences "Mario Serio", University of Florence, Florence, Italy

${ }^{3}$ Department of Pharmacology, Federal University of São Paulo, São Paulo, Brazil

Correspondence should be addressed to Diego Assis Gonçalves; diegoassisg@gmail.com

Received 24 December 2020; Revised 3 March 2021; Accepted 22 April 2021; Published 7 May 2021

Academic Editor: Hou De Zhou

Copyright ( 2021 Diego Assis Gonçalves et al. This is an open access article distributed under the Creative Commons Attribution License, which permits unrestricted use, distribution, and reproduction in any medium, provided the original work is properly cited.

\begin{abstract}
Brazil has the second highest number of deaths due to COVID-19. Obesity has been associated with an important role in disease development and a worse prognosis. We aimed to explore epidemiological data from Brazil, discussing the potential relationships between obesity and COVID-19 severity in this country. We used a public database made available by the Ministry of Health of Brazil (182700 patients diagnosed with COVID-19). Descriptive statistics were used to characterize our database. Continuous data were expressed as median and analyzed by the nonparametric tests Mann-Whitney or one-sample Wilcoxon. The frequencies of categorical variables have been analyzed by chi-square tests of independence or goodness-of-fit. Among the number of deaths, $74 \%$ of patients were 60 years of age or older. Patients with obesity who died of COVID-19 were younger ( 59 years (IQR $=23)$ ) than those without obesity ( 71 years $(\mathrm{IQR}=20), P<0.001$, and $\left.\eta^{2}=0.0424\right)$. Women with obesity who died of COVID-19 were older than men $\left(55\right.$ years $(\mathrm{IQR}=25)$ vs. $50(\mathrm{IQR}=22), P<0.001$, and $\left.\eta^{2}=0.0263\right)$. Furthermore, obesity increases the chances of needing intensive care unit (OR: 1.783, CI: 95\%, and $P<0.001$ ), needing ventilatory support (OR: $1.537, \mathrm{CI}: 95 \%$, and $P<0.001$ and OR: 2.302, CI: $95 \%$, and $P<0.001$, for noninvasive and invasive, respectively), and death (OR: $1.411, \mathrm{CI}: 95 \%$, and $P<0.001)$ of patients hospitalized with COVID-19. Our analysis supports obesity as a significant risk factor for the development of more severe forms of COVID-19. The present study can direct a more effective prevention campaign and appropriate management of subjects with obesity.
\end{abstract}

\section{Introduction}

The COVID-19 (coronavirus disease 2019) has been declared as a pandemic in March 2020 by the World Health Organization [1]. The disease is caused by severe acute respiratory syndrome coronavirus 2 (SARS-CoV-2), which belongs to the Coronaviridae family. To date, more than 70 million people worldwide have been confirmed to be infected, with 1,599,704 deaths [2-4]. Currently, Brazil is the country with the second highest number of fatalities and third highest total cases, 180,437 and 6,836,227, respectively $[2,5]$. More than 50,000 new cases keep on being reported per day in the country [5], and a high number of adults are considered at risk for severe COVID-19 in Brazil [6].

Since the beginning of the pandemic, studies have shown that the number of patients requiring intensive care, as well as the number of deaths, is greater among individuals over 60 years of age. Furthermore, these studies showed that some preexisting diseases can be considered risk factors, such as hypertension, diabetes, and cardiovascular disease [7-9]. Although obesity has not previously been reported among the main comorbidities related to COVID-19, it has an important role in the disease development and a worse prognosis [10-12]. This discussion proves to be very 
relevant, especially in the current pandemic scenario, since COVID-19 has been strongly affecting Brazil and the USA, both being populous countries where the obesity rate in adults reaches $22.1 \%$ and $36.2 \%$, respectively [13].

Obesity has recently been recognized by the World Obesity Federation as a chronic disease and defined in Western countries as an excessive fat accumulation in people with body mass index (BMI) equal to or higher than $30 \mathrm{~kg} / \mathrm{m}^{2}$ $[14,15]$. Currently, it represents a health, social, and economic emergency with an exponential epidemic growth: in 2016, approximately 2 billion adults worldwide were overweight and 650 million were with obesity $[14,16]$.

The etiology of obesity is multifactorial, and the imbalance among consumption and expenditure calories is essential for obesity development [17]. Biologically, obesity is a chronic lowgrade inflammatory state that alters metabolic and immunological pathways resulting in altered functions of the adipose tissue and also affecting other organs [18]. In this context, large amounts of cytokines and chemokines are released, and cells that produce proinflammatory molecules are recruited, culminating in unbalanced immune responses $[18,19]$.

The present study aims to explore epidemiological data from Brazil, discussing the potential relationships between obesity and COVID-19 severity in this country.

\section{Methods}

2.1. Data Sources. For the analysis performed in this study, we used a public database (SARS 2020-Severe Acute Respiratory Syndrome Database-including data from COVID-19), registered in the Influenza Epidemiological Surveillance Information System, SIVEP-Gripe (Sistema de Informação de Vigilância Epidemiológica da Gripe), and made available by the Ministry of Health of Brazil [20]. Since 2009, due to the Influenza A (H1N1) pandemic, the Ministry has been developing a SARS monitoring system. In 2020, the data from the pandemic COVID-19 were incorporated into the system. These data are regularly updated on the website, and we used those available by July 7, 2020. From the data provided, we used information about age, sex, presence/ absence of comorbidities (here, we considered the most frequent comorbidities: cardiovascular disease, diabetes, chronic kidney disease, chronic neurological disease, pneumopathy, obesity, immunosuppression, and asthma), case classification (SARS by influenza, SARS-CoV-2, or other types of the virus), patient's death or cure, and if there was a need for admission to the intensive care unit and (non) invasive ventilatory support. Only confirmed cases of COVID-19 were considered for this study as inclusion criteria.

We created two additional variables, hypertension and cancer, from a column identified as "other risk factors" containing several other diseases listed. For this reason, for these two diseases, only the "yes" (presence) information was indicated, and due to this limitation, they were excluded from some statistical analyses.

This work was developed using a public database that does not identify research participants; therefore, approval by an ethics committee is unnecessary.
2.2. Statistical Analysis. We used descriptive statistics to characterize our database. Due to the presence of outliers and the nonnormality of the distribution (assessed by the Kolmogorov-Smirnov test), the continuous variable (age) was expressed as median (interquartile range (IQR)) and analyzed by the nonparametric tests Mann-Whitney test or one-sample Wilcoxon test. The frequencies of categorical variables were analyzed by chi-square tests of independence or of goodness-of-fit. Multinomial logistic regressions were run using the need for ventilatory support as a dependent variable and age, sex, obesity, cardiovascular disease, and diabetes as independent variables. Binary logistic regressions were run using the outcome (alive or death) or the need for intensive unit care (yes or no) as dependent variables and age, sex, obesity, cardiovascular disease, and diabetes as independent variables. For all regression models, the only continuous variable (age) was standardized (Z-score) to obtain the standardized odds ratios. Statistical analysis was conducted with SPSS v.20, and the adopted statistical significance level was 0.05 .

Taking into consideration that in large samples, small effect sizes can be statistically significant [21], we also assess the following effect sizes to evaluate the magnitude of group differences and effects: eta squared $\left(\eta^{2}\right)$ for the Man$\mathrm{n}$-Whitney and Wilcoxon tests, Cramer's V for the chisquare tests, and standardized odds ratio (OR) for the logistic regression models. Eta squared and Cramer's $\mathrm{V}$ were calculated according to Fritz and colleagues and Kim, respectively $[22,23]$. Cohen's criteria were used to classify the effect sizes as small, medium, or large [22-24].

\section{Results}

3.1. Clinical and Demographic Characteristics of COVID-19 Mortality. Initially, we sought to describe the profile of the Brazilian population infected with COVID-19; a total of 182,700 patients infected with COVID-19 were included in this analysis. From the total confirmed deaths from COVID$19(61,829), 58 \%$ were men and $74 \%$ of patients were 60 years of age or older. The highest numbers of deaths were among patients with cardiovascular disease $(23,757)$, followed by diabetes $(19,000)$, hypertension $(8,475)$, chronic kidney disease $(3,836)$, chronic neurological disease $(3,476)$, pneumopathy $(3,090)$, obesity $(2,244)$, immunosuppression $(2,161)$, cancer $(2,155)$, and asthma $(1,192)$ (Table 1$)$.

\subsection{Patients with Obesity Who Died ofCOVID-19Are Younger} than Patients without Obesity. We first considered the effect of age dichotomizing the cohort of patients in two age groups, < and $\geq 60$ years old. As shown in Table 1, the proportion of deaths is significantly higher in the age group $\geq 60$ years (74\%). To further investigate the role of age and comorbidities in the death from COVID-19, we compared the frequency of deaths within each group of preexisting diseases, stratified by 60 -year-old cutoffs, by using the goodness-of-fit chi-square. Since the sample number is large, the $P$ value tends to be small $(<0.05)$ even when the difference between the groups is minimal. Thus, Cramer's V 
TABLE 1: Overview of the COVID-19-infected patients divided by sex, age group, and preexisting disease.

\begin{tabular}{|c|c|c|c|c|c|c|c|c|c|}
\hline & \multicolumn{3}{|c|}{ Alive } & \multicolumn{3}{|c|}{ Death } & \multicolumn{3}{|c|}{ Unknown } \\
\hline & $n$ & $\%$ & $\%$ valid cases & $n$ & $\%$ & $\%$ valid cases & $n$ & $\%$ & $\%$ valid cases \\
\hline \multicolumn{10}{|l|}{ Sex } \\
\hline Female & 34729 & 44.67 & 44.68 & 25745 & 41.64 & 41.65 & 18837 & 43.68 & 43.7 \\
\hline Male & 43001 & 55.31 & 55.32 & 36064 & 58.33 & 58.35 & 24272 & 56.28 & 56.3 \\
\hline Missing values & 16 & 0.02 & - & 20 & 0.03 & - & 16 & 0.04 & - \\
\hline \multicolumn{10}{|l|}{ Age } \\
\hline$<60$ & 50057 & 64.39 & 64.89 & 16135 & 26.1 & 26.15 & 24270 & 56.28 & 56.67 \\
\hline$\geq 60$ & 27080 & 34.83 & 35.11 & 45556 & 73.68 & 73.85 & 18559 & 43.04 & 43.33 \\
\hline Missing values & 609 & 0.78 & - & 138 & 0.22 & - & 296 & 0.69 & - \\
\hline \multicolumn{10}{|l|}{ Obesity } \\
\hline No & 21293 & 27.39 & 88.99 & 20623 & 33.35 & 90.19 & 12266 & 28.44 & 88.51 \\
\hline Yes & 2634 & 3.39 & 11.01 & 2244 & 3.63 & 9.81 & 1592 & 3.69 & 11.49 \\
\hline Missing values & 53819 & 69.22 & - & 38962 & 63.02 & - & 29267 & 67.87 & - \\
\hline \multicolumn{10}{|c|}{ Cardiovascular disease } \\
\hline No & 12343 & 15.88 & 37.42 & 10230 & 16.55 & 30.1 & 6732 & 15.61 & 35.32 \\
\hline Yes & 20642 & 26.55 & 62.58 & 23757 & 38.42 & 69.9 & 12327 & 28.58 & 64.68 \\
\hline Missing values & 44761 & 57.57 & - & 27842 & 45.03 & - & 24066 & 55.81 & - \\
\hline \multicolumn{10}{|l|}{ Diabetes } \\
\hline No & 14949 & 19.23 & 49.38 & 12754 & 20.63 & 40.17 & 8156 & 18.91 & 46.16 \\
\hline Yes & 15326 & 19.71 & 50.62 & 19000 & 30.73 & 59.83 & 9514 & 22.06 & 53.84 \\
\hline Missing values & 47471 & 61.06 & - & 30075 & 48.64 & - & 25455 & 59.03 & - \\
\hline \multicolumn{10}{|l|}{ Asthma } \\
\hline No & 22173 & 28.52 & 90.58 & 22050 & 35.66 & 94.87 & 12901 & 29.92 & 92.07 \\
\hline Yes & 2305 & 2.96 & 9.42 & 1192 & 1.93 & 5.13 & 1111 & 2.58 & 7.93 \\
\hline Missing values & 53268 & 68.52 & - & 38587 & 62.41 & - & 29113 & 67.51 & - \\
\hline \multicolumn{10}{|l|}{ Pneumopathy } \\
\hline No & 22524 & 28.97 & 92.28 & 20925 & 33.84 & 87.13 & 12821 & 29.73 & 91.4 \\
\hline Yes & 1884 & 2.42 & 7.72 & 3090 & 5 & 12.87 & 1206 & 2.8 & 8.6 \\
\hline Missing values & 53338 & 68.61 & - & 37814 & 61.16 & - & 29098 & 67.47 & - \\
\hline \multicolumn{10}{|c|}{ Chronic neurological disease } \\
\hline No & 22670 & 29.16 & 92.71 & 20795 & 33.63 & 85.68 & 12867 & 29.84 & 91.27 \\
\hline Yes & 1782 & 2.29 & 7.29 & 3476 & 5.62 & 14.32 & 1231 & 2.85 & 8.73 \\
\hline Missing values & 53294 & 68.55 & - & 37558 & 60.74 & - & 29027 & 67.31 & - \\
\hline \multicolumn{10}{|c|}{ Chronic kidney disease } \\
\hline No & 22301 & 28.68 & 92.03 & 20397 & 32.99 & 84.17 & 12570 & 29.15 & 89.46 \\
\hline Yes & 1930 & 2.48 & 7.97 & 3836 & 6.2 & 15.83 & 1481 & 3.43 & 10.54 \\
\hline Missing values & 53515 & 68.83 & - & 37596 & 60.81 & - & 29074 & 67.42 & - \\
\hline \multicolumn{10}{|c|}{ Immunosuppression } \\
\hline No & 22406 & 28.82 & 92.56 & 21349 & 34.53 & 90.81 & 12820 & 29.73 & 92.08 \\
\hline Yes & 1800 & 2.32 & 7.44 & 2161 & 3.5 & 9.19 & 1102 & 2.56 & 7.92 \\
\hline Missing values & 53540 & 68.87 & - & 38319 & 61.98 & - & 29203 & 67.72 & - \\
\hline \multicolumn{10}{|l|}{ Hypertension } \\
\hline Yes & 7694 & 9.9 & 100 & 8475 & 13.71 & 100 & 4227 & 9.8 & 100 \\
\hline Missing values & 70052 & 90.1 & - & 53354 & 86.29 & - & 38898 & 90.2 & - \\
\hline \multicolumn{10}{|l|}{ Cancer } \\
\hline Yes & 1155 & 1.49 & 100 & 2155 & 3.49 & 100 & 723 & 1.68 & 100 \\
\hline Missing values & 76591 & 98.51 & - & 59674 & 96.51 & - & 42402 & 98.32 & - \\
\hline
\end{tabular}

effect size was also calculated. Considering the number of degrees of freedom in the analysis, Cramer's V is considered negligible below 0.1 [24]. Interestingly, among the variables analyzed, obesity was the only one for which no difference was present in the number of deaths between the two age groups. For all the other variables, the number of deaths was higher in the $\geq 60$ years age group (Table 2 ).

Then, we compared the median age of patients who died of COVID-19 in each preexisting comorbidity (Table 3), also calculating the "eta squared" $\left(\eta^{2}\right)$, an effect size suitable for the Mann-Whitney test. In case $\eta^{2}$ is between 0.01 and 0.06 , the difference among the groups is considered small. If between 0.06 and 0.14 , the difference is average, and above 0.14 is large [24]. Therefore, differences with $\eta^{2}<0.01$ were considered nonsignificant.

A statistically significant difference in the age distribution was found for obesity, as the median age of patients with obesity was significantly lower $(59$ years $(I Q R=23))$ than 
TABLe 2: Deaths by COVID-19 within preexisting diseases and age group.

\begin{tabular}{|c|c|c|c|c|c|c|}
\hline & \multicolumn{3}{|c|}{ Age (years) } & \multirow{2}{*}{$\mathrm{X}^{2}$} & \multirow{2}{*}{$P$} & \multirow{2}{*}{ Cramer's V } \\
\hline & $<60$ & $\geq 60$ & Total & & & \\
\hline All deaths* & 16130 & 45541 & 61671 & 14031.14 & $<0.001$ & 0.4770 \\
\hline Obesity & 1124 & 1120 & 2244 & 0.007 & 0.933 & 0.0018 \\
\hline Cardiovascular disease $^{*}$ & 4167 & 19562 & 23729 & 9993.29 & $<0.001$ & 0.6490 \\
\hline Diabetes $^{*}$ & 4175 & 14804 & 18979 & 5958.31 & $<0.001$ & 0.5603 \\
\hline Asthma* & 414 & 778 & 1192 & 111.154 & $<0.001$ & 0.3054 \\
\hline Pneumopathy ${ }^{*}$ & 459 & 2622 & 3081 & 1519.43 & $<0.001$ & 0.7023 \\
\hline Neurological disease* & 2355 & 8350 & 10705 & 2094.64 & $<0.001$ & 0.4423 \\
\hline Immunosuppression* & 798 & 1355 & 2153 & 144.552 & $<0.001$ & 0.2591 \\
\hline Chronic kidney disease* & 971 & 2863 & 3834 & 935.15 & $<0.001$ & 0.4939 \\
\hline Hypertension* & 1694 & 6778 & 8472 & 3048.6 & $<0.001$ & 0.5999 \\
\hline Cancer* & 563 & 1592 & 2155 & 491.342 & $<0.001$ & 0.4775 \\
\hline
\end{tabular}

Goodness-of-fit chi-square test. ${ }^{*}$ Cramer's V $>0.1$.

TABLE 3: Median age of death in subgroups with and without comorbidities.

\begin{tabular}{|c|c|c|c|c|c|c|}
\hline & Median & IQR & $\mathrm{Z}$ & $P$ & $N$ & Eta squared \\
\hline Obesity* & - & - & 31.095 & $<0.001$ & 22821 & 0.0424 \\
\hline Yes & 59 & 23 & - & - & - & - \\
\hline No & 71 & 20 & - & - & - & - \\
\hline Cardiovascular disease ${ }^{*}$ & - & - & -27.926 & $<0.001$ & 33929 & 0.0230 \\
\hline Yes & 73 & 18 & - & - & - & - \\
\hline No & 68 & 22 & - & - & - & - \\
\hline Asthma & - & - & 7.876 & $<0.001$ & 23196 & 0.0027 \\
\hline Yes & 67 & 25 & - & - & - & - \\
\hline No & 71 & 20 & - & - & - & - \\
\hline Diabetes & - & - & 5.157 & $<0.001$ & 31697 & 0.0008 \\
\hline Yes & 70 & 18 & - & - & - & - \\
\hline No & 71 & 22 & - & - & - & - \\
\hline Neurological disease ${ }^{*}$ & - & - & -35.559 & $<0.001$ & 24224 & 0.0522 \\
\hline Yes & 80 & 16 & - & - & - & - \\
\hline No & 70 & 20 & - & - & - & - \\
\hline Pneumopathy & - & - & -13.783 & $<0.001$ & 23966 & 0.0079 \\
\hline Yes & 74 & 17 & - & - & - & - \\
\hline No & 70 & 21 & - & - & - & - \\
\hline Immunosuppression * & - & - & 16.474 & $<0.001$ & 23463 & 0.0116 \\
\hline Yes & 65 & 22 & - & - & - & - \\
\hline No & 71 & 20 & - & - & - & - \\
\hline Chronic kidney disease & - & - & 3.46 & $<0.001$ & 24817 & 0.0005 \\
\hline Yes & 69 & 20 & - & - & - & - \\
\hline No & 71 & 20 & - & - & - & - \\
\hline Sex & - & - & -23.486 & $<0.001$ & 61671 & 0.0089 \\
\hline $\mathrm{F}$ & 72 & 21 & - & - & - & - \\
\hline M & 69 & 20 & - & - & - & - \\
\hline
\end{tabular}

F: females; IQR: interquartile range; M: males. Mann-Whitney test. ${ }^{*}$ Eta squared $\left(\eta^{2}\right)>0.01$.

that of subjects without obesity (71 years $(\mathrm{IQR}=20)$, $P<0.001$, and $\left.\eta^{2}=0.0424\right)$. The same was found for immunosuppression $(65$ years $(\mathrm{IQR}=22)$ vs. 71 years $(\mathrm{IQR}=20), \quad P<0.001$, and $\left.\eta^{2}=0.0116\right)$. Conversely, the median age was higher in patients who had cardiovascular disease $(73$ years $(\mathrm{IQR}=18)$ vs. 68 years $(\mathrm{IQR}=22)$, $P<0.001$, and $\left.\eta^{2}=0.0230\right)$ and neurological disease $(80$ years $(\mathrm{IQR}=16)$ vs. 70 years $(\mathrm{IQR}=20), P<0.001$, and $\eta^{2}=0.0522$ ) (Table 3 ).

Our next step was to assess whether there is a difference between the median age of the total number of subjects who died of COVID-19 (70 years) and the median age of dead patients in each group of preexisting diseases. The Wilcoxon sign test was used, the "eta square" was applied as the effect size, and $\eta^{2}<0.01$ corresponds to nonsignificant differences. We observed that patients with obesity (59 years $(\mathrm{IQR}=23)$, $P<0.001$, and $\left.\eta^{2}=0.3518\right)$, asthma (67 years $(\mathrm{IQR}=25)$, $P<0.001$, and $\eta^{2}=0.0607$ ), immunosuppression (65 years (IQR $=22), P<0.001$, and $\left.\eta^{2}=0.1235\right)$, and cancer (69 years $(\mathrm{IQR}=19), P<0.001$, and $\eta^{2}=0.0113$ ) have age medians below the general median of 70 years (Figure 1 and Table S1). Conversely, the median age in cardiovascular disease (73 


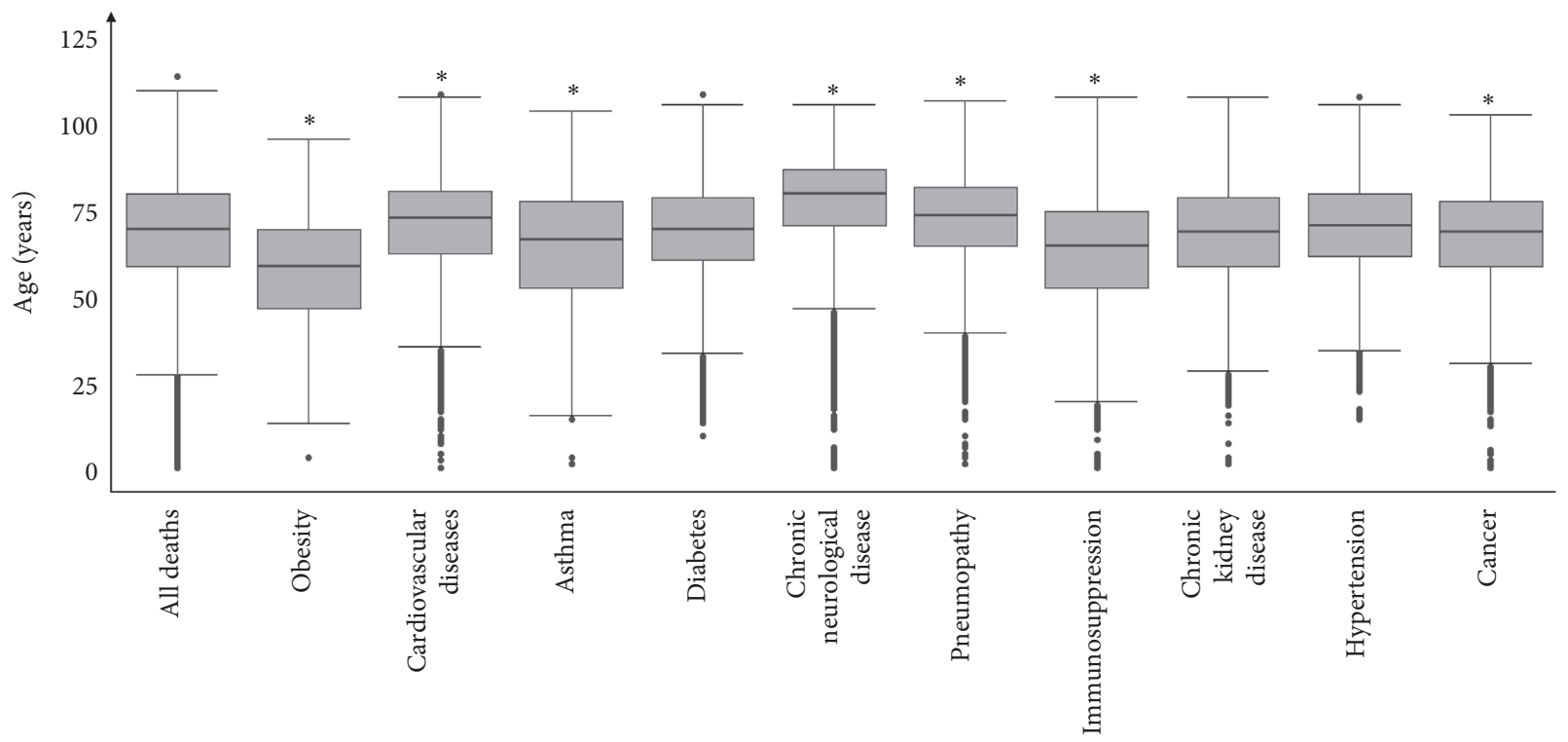

FIGURE 1: Comparison between the median age of death in the subgroups with comorbidity vs. the overall median age of death (70 years old). Obesity $(n=2244)$, cardiovascular disease $(n=23735)$, asthma $(n=1192)$, diabetes $(n=18986)$, neurological disease $(n=3470)$, pneumopathy $(n=3082)$, immunosuppression $(n=2154)$, chronic kidney disease $(n=3836)$, hypertension $(n=8475)$, cancer $(n=2155)$, and all deaths $(n=61829)$. One-sample Wilcoxon test. ${ }^{*}$ Eta squared $\left(\eta^{2}\right)>0 \cdot 01$.

years $(\mathrm{IQR}=18), P<0.001$, and $\left.\eta^{2}=0.0227\right)$ and pneumopathy (74 years $(\mathrm{IQR}=17), P<0.001$, and $\left.\eta^{2}=0.0585\right)$ was higher than the median age of total cases (Figure 1 and Table S1). Among the comorbidities analyzed, obesity had the greatest effect size $\left(\eta^{2}=0.3518\right)$, which means that patients with obesity who died of COVID-19 had the highest difference in age compared to the median age of the total cohort of dead subjects (Table S1).

3.3. Women with Obesity Who Died of COVID-19 Are Older than Men with Obesity. Our next objective was to identify how COVID-19 deaths are distributed, considering the age and sex of the patients. First, we assessed whether the median age was different between men and women within each group of comorbidities by using Mann-Whitney's $U$ test and calculating the "eta square." Women have a median age higher than men when considering obesity, neurological disease, and hypertension ( $(55$ years $(\mathrm{IQR}=25)$ vs. 50 $(\mathrm{IQR}=22), P<0.001$, and $\left.\eta^{2}=0.0263\right),(80$ years $(\mathrm{IQR}=20)$ vs. 74 years $(\mathrm{IQR}=22), P<0.001$, and $\left.\eta^{2}=0.0333\right)$, and $(67$ years $(\mathrm{IQR}=21)$ vs. 65 years $(\mathrm{IQR}=20), P<0.001$, and $\left.\eta^{2}=0.0114\right)$, respectively). However, for cancer patients, the median age of men was higher than that of women (70 years $(\mathrm{IQR}=18)$ vs. 63 years $(\mathrm{IQR}=23), \quad P<0.001$, and $\eta^{2}=0.0301$ ) (Figure 2 and Table S2).

In addition, we used the chi-square associated with Cramer's $V$ to perform a statistical analysis of the frequency of deaths for each comorbidity. We found that the number of women with obesity who died in the age group $\geq 60$ years was higher than expected and the number of men who died in the same age group was lower than expected $(P<0.001$, Cramer's $V=0.1370$ ) (Table 4 ). Conversely, in cancer patients, the number of women who died in the age group $\geq 60$ years was lower than expected $(P<0.001$, Cramer's
$\mathrm{V}=0.1480$ ). No other disease showed a significant association between sex and age group (Table 4).

3.4. Obesity Is Associated with an Increase in ICU Need, Ventilatory Support, and Death of Hospitalized Patients with COVID-19. Through logistic regression analysis, we evaluated the influence of obesity as a risk factor for ventilatory support, intensive unit care (ICU) admission, and death. Obesity significantly increased the risk of using noninvasive (OR: 1.537; 95\% CI: 1.414-1.670; $P<0.001$ ) and even more invasive mechanical ventilatory support (OR: 2.302; 95\% CI: 2.104-2.518; $P<0.001$ ) (Table 5). Also, age increased the risk for both levels of ventilation needs (OR: 1.331; 95\% CI: 1.301-1.363; $P<0.001$ and OR: 1.504 ; 95\% CI: $1.463-1.547$; $P<0.001$, for noninvasive and invasive, respectively) (Table 5). Besides, individuals with obesity are more likely to require ICU (OR: 1.783; 95\% CI: 1.672-1.903; $P<0.001$ ). Similarly, the risk of ICU admission increased with age (OR: 1.195; 95\% CI: $1.171-1.220 ; P<0.001$ ) (Table 6). Both obesity and age also increased the patients' risk of dying of COVID19 (OR: 1.411; 95\% CI: $1.309-1.521 ; P<0.001)$ and (OR: 2.354; 95\% CI: 2.295-2.414; $P<0.001$ ), respectively (Table 7). The risk of mechanical ventilatory support need (OR: 0.949; 95\% CI: 0.911-0.989; and P 0.013 and OR: 0.806; 95\% CI: $0.768-0.845$; and $P<0.001$, for noninvasive and invasive, respectively), ICU admission (OR: 0.842; 95\% CI: $0.812-0.872$; and $P<0.001$ ), and death of COVID-19 (OR: 0.784; 95\% CI: $0.753-0.816$; and $P<0.001)$ is higher in men than in women (Tables 5-7). Furthermore, we evaluated the effect of the two most frequent preexisting comorbidities present in our cohort, cardiovascular disease and diabetes. Our results showed that the influence of cardiovascular disease and diabetes were less effective for COVID-19 severity than obesity (cardiovascular disease: OR: 1.203; 95\% 


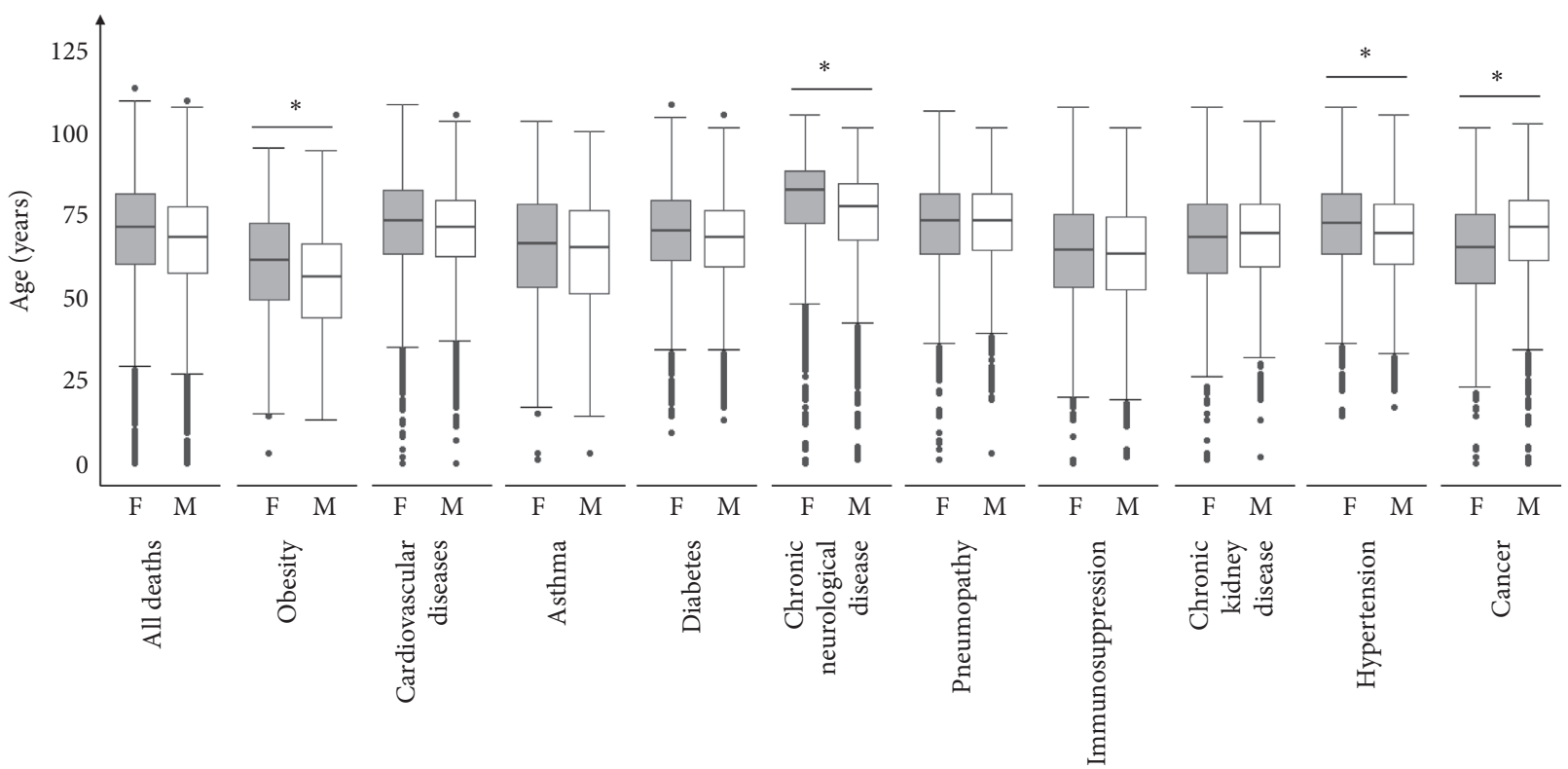

Figure 2: Comparison between men and women median age of death within each comorbidity subgroup and for all deaths. Obesity $(n=2244)$, cardiovascular disease $(n=23729)$, asthma $(n=1192)$, diabetes $(n=18979)$, neurological disease $(n=3470)$, pneumopathy ( $n=3081)$, immunosuppression $(n=2153)$, chronic kidney disease $(n=3834)$, hypertension $(n=8472)$, cancer $(n=2155)$, and all deaths $(n=61671)$. F: females; M: males. Mann-Whitney test. ${ }^{*}$ Eta squared $\left(\eta^{2}\right)>0 \cdot 01$.

TABLE 4: Frequencies of death in men and women with comorbidities by age group.

\begin{tabular}{|c|c|c|c|c|c|c|}
\hline & \multicolumn{3}{|c|}{ Age (years) } & \multirow{2}{*}{$\mathrm{X}^{2}$} & \multirow{2}{*}{$P$} & \multirow{2}{*}{ Cramer's V } \\
\hline & $<60$ & $\geq 60$ & Total & & & \\
\hline All deaths & - & - & - & \multirow{4}{*}{193.205} & \multirow{4}{*}{$<0.001$} & \multirow{4}{*}{0.0560} \\
\hline $\mathrm{F}$ & 5968 & 19711 & 25679 & & & \\
\hline M & 10162 & 25830 & 35992 & & & \\
\hline Total & 16130 & 45541 & 61671 & & & \\
\hline Obesity* & - & - & - & \multirow{4}{*}{41.728} & \multirow{4}{*}{$<0.001$} & \multirow{4}{*}{0.1370} \\
\hline $\mathrm{F}$ & 470 & 622 & 1092 & & & \\
\hline $\mathrm{M}$ & 654 & 498 & 1152 & & & \\
\hline Total & 1124 & 1120 & 2244 & & & \\
\hline Cardiovascular disease & - & - & - & \multirow{4}{*}{37.517} & \multirow{4}{*}{$<0.001$} & \multirow{4}{*}{0.0400} \\
\hline $\mathrm{F}$ & 1647 & 8749 & 10396 & & & \\
\hline $\mathrm{M}$ & 2520 & 10813 & 13333 & & & \\
\hline Total & 4167 & 19562 & 23729 & & & \\
\hline Diabetes & - & - & - & \multirow{4}{*}{47.129} & \multirow{4}{*}{$<0.001$} & \multirow{4}{*}{0.0500} \\
\hline F & 1695 & 6899 & 8594 & & & \\
\hline M & 2480 & 7905 & 10385 & & & \\
\hline Total & 4175 & 14804 & 18979 & & & \\
\hline Asthma & - & - & - & \multirow{4}{*}{0.023} & \multirow{4}{*}{0.879} & \multirow{4}{*}{0.0060} \\
\hline $\mathrm{F}$ & 232 & 441 & 673 & & & \\
\hline $\mathrm{M}$ & 182 & 337 & 519 & & & \\
\hline Total & 414 & 778 & 1192 & & & \\
\hline Pneumopathy & - & - & - & \multirow{4}{*}{5.742} & \multirow{4}{*}{0.017} & \multirow{4}{*}{0.0440} \\
\hline $\mathrm{F}$ & 208 & 1029 & 1237 & & & \\
\hline $\mathrm{M}$ & 251 & 1593 & 1844 & & & \\
\hline Total & 459 & 2622 & 3081 & & & \\
\hline Neurological disease & - & - & - & \multirow{4}{*}{14.885} & \multirow{4}{*}{$<0.001$} & \multirow{4}{*}{0.0660} \\
\hline $\mathrm{F}$ & 154 & 1552 & 1706 & & & \\
\hline $\mathrm{M}$ & 233 & 1531 & 1764 & & & \\
\hline Total & 387 & 3083 & 3470 & & & \\
\hline
\end{tabular}


TABLE 4: Continued.

\begin{tabular}{|c|c|c|c|c|c|c|}
\hline & \multicolumn{3}{|c|}{ Age (years) } & \multirow{2}{*}{$\mathrm{X}^{2}$} & \multirow{2}{*}{$P$} & \multirow{2}{*}{ Cramer's V } \\
\hline & $<60$ & $\geq 60$ & Total & & & \\
\hline Immunosuppression & - & - & - & \multirow{4}{*}{0.499} & \multirow{4}{*}{0.48} & \multirow{4}{*}{0.0160} \\
\hline $\mathrm{F}$ & 353 & 622 & 975 & & & \\
\hline $\mathrm{M}$ & 445 & 733 & 1178 & & & \\
\hline Total & 798 & 1355 & 2153 & & & \\
\hline Chronic kidney disease & - & - & - & \multirow{4}{*}{6.972} & \multirow{4}{*}{0.008} & \multirow{4}{*}{0.0430} \\
\hline $\mathrm{F}$ & 412 & 1076 & 1488 & & & \\
\hline $\mathrm{M}$ & 559 & 1787 & 2346 & & & \\
\hline Total & 971 & 2863 & 3834 & & & \\
\hline Hypertension & - & - & - & \multirow{4}{*}{31.667} & \multirow{4}{*}{$<0.001$} & \multirow{4}{*}{0.0610} \\
\hline $\mathrm{F}$ & 635 & 3057 & 3692 & & & \\
\hline $\mathrm{M}$ & 1059 & 3721 & 4780 & & & \\
\hline Total & 1694 & 6778 & 8472 & & & \\
\hline Cancer* & - & - & - & \multirow{4}{*}{46.442} & \multirow{4}{*}{$<0.001$} & \multirow{4}{*}{0.1480} \\
\hline $\mathrm{F}$ & 330 & 666 & 996 & & & \\
\hline $\mathrm{M}$ & 233 & 926 & 1159 & & & \\
\hline Total & 563 & 1592 & 2155 & & & \\
\hline
\end{tabular}

F: females; M: males. Chi-square of independence test. ${ }^{*}$ Cramer's V $>0.1$.

TABLE 5: Multinomial logistic regression with ventilatory support as the dependent variable and age, sex, obesity, cardiovascular disease, and diabetes as independent variables.

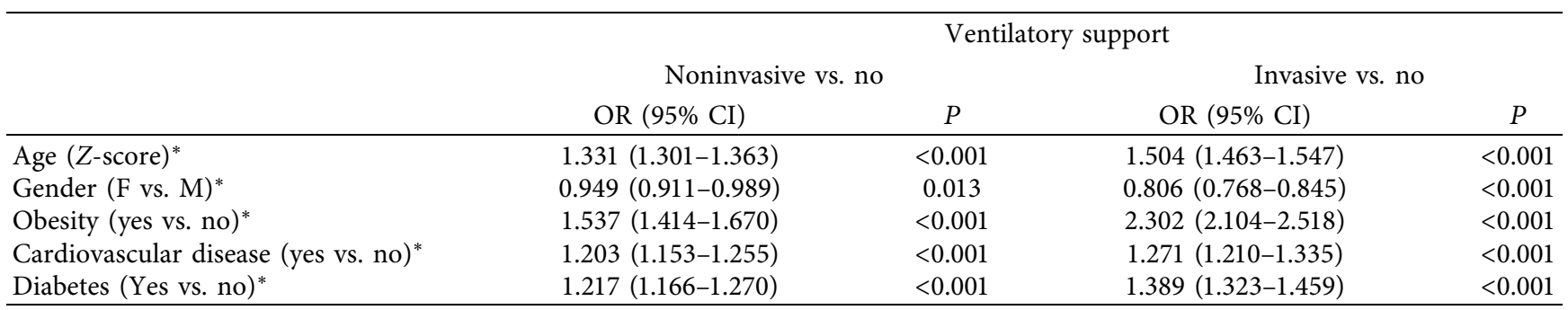

CI: confidence interval; F: females; M: males; OR: odds ratio. ${ }^{*}, P<0.05$.

TABLE 6: Binary logistic regression with the need of ICU (yes vs. no) as the dependent variables and age, sex, obesity, cardiovascular disease, and diabetes as independent variables.

\begin{tabular}{|c|c|c|}
\hline & \multicolumn{2}{|c|}{ ICU (yes vs. no) } \\
\hline & OR $(95 \% \mathrm{CI})$ & $P$ \\
\hline Age $(Z \text {-score })^{*}$ & $1.195(1.171-1.220)$ & $<0.001$ \\
\hline Gender $(\mathrm{F} \text { vs. } \mathrm{M})^{*}$ & $0.842(0.812-0.872)$ & $<0.001$ \\
\hline Obesity (yes vs. no)* & $1.783(1.672-1.903)$ & $<0.001$ \\
\hline Cardiovascular disease (yes vs. no)* & $1.161(1.119-1.204)$ & $<0.001$ \\
\hline Diabetes (yes vs. no) ${ }^{*}$ & $1.128(1.088-1.169)$ & $<0.001$ \\
\hline
\end{tabular}

CI: confidence interval; F: females; M: males; ICU: intensive care unit; OR: odds ratio. ${ }^{*}, P<0.05$.

CI: $1.153-1.255 ; P<0.001$ for noninvasive and OR: 1.271 ; 95\% CI: $1.210-1.335 ; P<0.001$ for invasive ventilatory support; OR: 1.161; 95\% CI: 1.119-1.204; $P<0.001$ for ICU, and OR: 0.975 ; 95\% CI: $0.936-1.015 ; P 0.219$ for death; diabetes: OR: 1.217; 95\% CI: $1.166-1.270 ; P<0.001$ for noninvasive and OR: $1.389 ; 95 \% \mathrm{CI}: 1.323-1.459 ; P<0.001$ for invasive ventilatory support; OR: 1.128 ; $95 \% \mathrm{CI}$ : 1.088-1.169; $P<0.001$ for ICU, and OR: $1.224 ; 95 \%$ CI: 1.176-1.274; $P<0.001$ for death) (Tables $5-7$ ).
TABLE 7: Binary logistic regression with the outcome (death vs. alive) as the dependent variables, and age, sex, obesity, cardiovascular disease, and diabetes as independent variables.

\begin{tabular}{|c|c|c|}
\hline & \multicolumn{2}{|c|}{ Outcome (death vs. alive) } \\
\hline & OR $(95 \% \mathrm{CI})$ & $P$ \\
\hline Age $(Z \text {-score })^{*}$ & $2.354(2.295-2.414)$ & $<0.001$ \\
\hline Gender (F vs. $M)^{*}$ & $0.784(0.753-0.816)$ & $<0.001$ \\
\hline Obesity (yes vs. no)* & $1.411(1.309-1.521)$ & $<0.001$ \\
\hline Cardiovascular disease (yes vs. no) & $0.975(0.936-1.015)$ & 0.219 \\
\hline Diabetes (yes vs. no)* & $1.224(1.176-1.274)$ & $<0.001$ \\
\hline
\end{tabular}

CI: confidence interval; F: females; M: males; and OR: odds ratio. ${ }^{*}, P<0.05$.

\section{Discussion}

The development of more severe forms of COVID-19 in patients with obesity has been attributed to different mechanisms. The state of low-grade chronic inflammation characterizing obesity and the consequent development of immune dysfunction and insulin resistance, the high levels of angiotensin-converting enzyme (ACE2) produced by the expanded mass of adipose tissue, used by the virus to infect 
the host cells, the impaired lung function, and intestinal dysbiosis are among them. In addition, other obesity-associated comorbidities may also represent risk factors for COVID-19, such as diabetes, cardiovascular disease, and hypertension [19, 25-28].

Here, we showed that among the main diseases considered as a risk factor for COVID-19, obesity was the only one that showed no statistically significant difference in the number of deaths between patients stratified in $<60$ and $\geq 60$ years of age (Table 2). Moreover, when considering the median age of the deaths, individuals with obesity died younger than individuals without obesity (Table 3 ) and had a median age lower than that of the total deaths, being the comorbidity where this difference was the most significant (Figure 1 and Table S1). Overall, our results indicate that obesity is an important risk factor for COVID-19 that seem to be more evident in the population under 60 years of age. These findings are consistent with other studies [12, 29, 30]. For instance, Kass and colleagues found an inverse correlation between age and BMI of patients in an American cohort of 265 patients with COVID-19 admitted to ICU; in this cohort, obesity was more diffuse in the younger individuals [30].

Similarly, analyzing data of COVID-19-positive patients from a hospital system in New York City, a study showed that among patients younger than 60 years, subjects with a BMI among $30-34 \mathrm{Kg} / \mathrm{m}^{2}$ were 2.0 times more likely to be admitted to acute care and 1.8 times more likely to be in critical care when compared to subjects with a BMI $<30 \mathrm{Kg} /$ $\mathrm{m}^{2}$. The risk of being admitted to acute care and critical care was raised to 2.2 and 3.6 times, respectively, for $\mathrm{BMI}>35 \mathrm{Kg} /$ $\mathrm{m}^{2}$ in the same age group [12]. In another study performed in Wuhan (China) on patients with COVID-19 between 18 and 40 years of age, severe and critical cases had a significantly higher BMI than patients of moderate cases [29].

Thus, according to our data and supported by these findings in the literature, while age is an important risk factor for dying of COVID-19 in association with other comorbidities, this might not be true for obesity. Patients with obesity died of COVID-19 were younger than subjects without obesity, compared to the median age of all the other comorbidities considered in this study.

Considering sex, in our analysis, women with obesity had a significantly higher median age of death when compared to men (Figure 2 and Table S2). Also, comparing the frequency of COVID-19 dead men and women in the groups $<60$ and $\geq 60$ years of age, we demonstrated that obesity and cancer were the only diseases that showed a significant difference between the observed and expected frequencies. Reinforcing our median analyses, the observed number of deaths of women with obesity in the age group $\geq 60$ years was higher than expected (Table 4 ).

Previous studies have shown that the transmembrane protein ACE2 plays a key role in the pathogenesis of COVID-19, favoring the virus' entry into the host cell $[31,32]$. Recently, its expression in the adipose tissue has been associated with the worst prognosis observed in patients with obesity affected by COVID-19 [33-35]. No difference in ACE2 expression has been observed between adipose tissue cells of individuals with and without obesity [36]. However, subjects with obesity have more adipose tissue than lean subjects and consequently more adipocytes with ACE2 receptors, resulting in a significant increase in the viral load and an exacerbation of the inflammatory status $[36,37]$. ACE2 has been shown to be more expressed in the visceral adipose tissue (VAT) than in the subcutaneous fat [38], supporting the concept that the extent of the visceral adipose mass might be related to COVID-19 severity. Recently, Deng and colleagues found that this type of fat worsens the disease in young adults [29]. Another study showed that the amount of VAT is associated with a greater need for ICU and mechanical ventilation in patients with COVID-19 [39]. It is also important to note that excess adipose tissue, especially VAT, is associated with chronic low-grade inflammation present in obese individuals [40]. It is well established that metabolic disorders and the imbalance of the immune system resulting from this process play an important role in the relationship between obesity and other comorbidities [18]. Recently, some studies indicated these dysfunctions as responsible for developing more severe forms of COVID-19 in patients with obesity. However, the pathophysiological mechanisms underlying this putative relation have not yet been elucidated $[27,28]$.

During menopause, there is a reduction in estrogen and progesterone levels in women, which causes an increase in the extension of the visceral fat mass [41]. This increase in visceral fat mass might explain why women with obesity die of COVID-19 older than men. Also, a protective capacity of estrogen against disease development has been suggested as an advantage towards the male sex $[42,43]$.

Finally, according to our analysis, patients with obesity are more likely to be admitted to the ICU, to require mechanical ventilation, and to die of COVID-19 than individuals without obesity. In addition, our results showed that obesity is related to the severity of COVID-19 more than cardiovascular diseases and diabetes (Tables 5-7). These findings are in agreement with other studies present in the recent literature. The retrospective cohort study of patients admitted to intensive care for SARS-CoV-2 in a French hospital showed that individuals who needed invasive mechanical ventilation had a higher BMI than those who did not [10]. Also, the number of patients requiring invasive mechanical ventilation during hospitalization in intensive care was positively correlated with the BMI, reaching more than $85.7 \%$ in the BMI group $\geq 35 \mathrm{Kg} / \mathrm{m}^{2}$ [10]. Similarly, other studies performed on COVID-19 patients in different countries listed obesity as one of the main risk factors associated with hospitalization and the critical evolution of the disease $[11,44,45]$.

We recognize that our study has some limitations. First, the high frequency of missing or ignored values. As it is a public database, adequate control over data filling cannot be guaranteed and much information about the presence or absence of comorbidities is absent or has been ignored. Second, unfortunately, there is no information in the database that would be relevant to discuss this study and understanding the development of severe forms of COVID19 , such as cytokine levels, inflammatory markers, and other 
laboratory indexes. Although a column for BMI values is present, we decided not to use it because we found the data inconsistent. Finally, it is essential to consider underreporting cases of COVID-19 in the country. Despite these points, our study has a significant number of patients and valuable information for a better understanding of some epidemiological aspects of the disease.

\section{Conclusions}

Despite the lower frequency of COVID-19 cases and deaths in obesity than other comorbidities, this pathology represents a pivotal factor associated with the critical evolution of the disease. We showed that COVID-19 patients with obesity die younger than individuals without obesity and women with obesity die older than men. These differences may be due to a different distribution of visceral adipose tissue and levels of sex steroid hormones, in particular, estrogens, characterizing obesity and sex. Also, in COVID19 patients, obesity has been associated with an increased risk of ICU admittance, needs of mechanical ventilation, and death. It is essential to consider obesity as a warrant public health problem due to the significant impact of this disease in worsening pathologies as COVID-19. Additional effective actions and health/social policy more focused on fighting the obesity epidemic are urgently needed in the light of the tremendous impact of this chronic disease on COVID-19 and possible upcoming viral epidemics.

\section{Data Availability}

All data used to support the findings of this study are available from the corresponding author upon request.

\section{Conflicts of Interest}

The authors declare that they have no conflicts of interest regarding the publication of this paper.

\section{Authors' Contributions}

Michaela Luconi and Jacy Gameiro contributed equally to this work. DAG was responsible for study design, data analysis, data interpretation, and manuscript writing. AG and VR were responsible for manuscript writing and data interpretation. FFP was responsible for data and statistical analysis. ML and JG were responsible for data interpretation and manuscript review.

\section{Acknowledgments}

DAG was supported by Coordenação de Aperfeiçoamento de Pessoal de Nível Superior (CAPES), Brazil.

\section{Supplementary Materials}

Table S1. Comparison between the median age of death in the different comorbidity subgroups vs. the overall median age of death ( 70 years old). Table S2. Comparison between men and women median age of death within each comorbidity subgroup. (Supplementary Materials)

\section{References}

[1] "Coronavirus disease (COVID-19) [Internet]," 2020, https:// www.who.int/emergencies/diseases/novel-coronavirus-2019.

[2] WHO Coronavirus Disease (COVID-19) Dashboard, "WHO coronavirus disease (COVID-19) Dashboard [Internet]," 2020, https://covid19.who.int/table.

[3] K. Renu, P. L. Prasanna, and A. Valsala Gopalakrishnan, "Coronaviruses pathogenesis, comorbidities and multi-organ damage - a review," Life Sciences, vol. 255, p. 117839, 2020.

[4] T. Singhal, "A review of coronavirus disease-2019 (COVID19)," The Indian Journal of Pediatrics, vol. 87, no. 4, pp. 281-286, 2020.

[5] "Coronavírus Brasil [Internet]," 2020, https://covid.saude. gov.br/.

[6] L. F. M. Rezende, B. Thome, M. C. Schveitzer, P. R. B. De Souza-Júnior, and C. L. Szwarcwald, "Adults at high-risk of severe coronavirus disease-2019 (Covid-19) in Brazil,” Revista de Saude Publica, vol. 54, p. 50, 2020.

[7] F. Zhou, T. Yu, R. Du et al., "Clinical course and risk factors for mortality of adult inpatients with COVID-19 in Wuhan, China: a retrospective cohort study," The Lancet, vol. 395, no. 10229, pp. 1054-1062, 2020.

[8] G. Grasselli, A. Zangrillo, A. Zanella et al., "Baseline characteristics and outcomes of 1591 patients infected with SARSCoV-2 admitted to ICUs of the Lombardy region, Italy," JAMA, vol. 323, no. 16, pp. 1574-1581, 2020.

[9] P. K. Bhatraju, B. J. Ghassemieh, M. Nichols et al., "Covid-19 in critically ill patients in the Seattle region - case series," New England Journal of Medicine, vol. 382, no. 21, pp. 2012-2022, 2020.

[10] A. Simonnet, M. Chetboun, J. Poissy et al., "High prevalence of obesity in severe acute respiratory syndrome coronavirus-2 (SARS-CoV-2) requiring invasive mechanical ventilation," Obesity, vol. 28, no. 7, pp. 1195-1199, 2020.

[11] C. M. Petrilli, S. A. Jones, J. Yang et al., "Factors associated with hospital admission and critical illness among 5279 people with coronavirus disease 2019 in New York City: prospective cohort study," BMJ, vol. 369, p. m1966, 2020.

[12] J. Lighter, M. Phillips, S. Hochman et al., "Obesity in patients younger than 60 years is a risk factor for COVID-19 hospital admission," Clinical Infectious Diseases, vol. 71, no. 15, pp. 896-897, 2020.

[13] WHO, "Overweight and obesity [Internet]," 2020, https://www. who.int/gho/ncd/risk_factors/overweight_obesity/obesity_adults/ en/.

[14] "Obesity and overweight [Internet]," 2020, https://www.who. int/news-room/fact-sheets/detail/obesity-and-overweight.

[15] G. A. Bray, K. K. Kim, and J. P. H. Wilding, "Obesity: a chronic relapsing progressive disease process. A position statement of the World Obesity Federation," Obesity Reviews, vol. 18, no. 7, pp. 715-723, 2017.

[16] P. González-Muniesa, M. A. Mártinez-González, F. B. Hu et al., "Obesity," Nature Reviews Disease Primers, vol. 3, 2017.

[17] M. Blüher, "Obesity: global epidemiology and pathogenesis," Nature Reviews Endocrinology, vol. 15, no. 5, pp. 288-298, 2019.

[18] A. R. Saltiel and J. M. Olefsky, "Inflammatory mechanisms linking obesity and metabolic disease," Journal of Clinical Investigation, vol. 127, no. 1, pp. 1-4, 2017. 
[19] E. Korakas, I. Ikonomidis, F. Kousathana et al., "Obesity and COVID-19: immune and metabolic derangement as a possible link to adverse clinical outcomes," American Journal of Physiology-Endocrinology and Metabolism, vol. 319, no. 1, pp. E105-E109, 2020.

[20] "SRAG 2020 - Banco de Dados de Síndrome Respiratória Aguda Grave - incluindo dados da COVID-19 - Conjuntos de dados - open data [Internet]," 2020, https://opendatasus. saude.gov.br/dataset/bd-srag-2020.

[21] M. S. Thiese, B. Ronna, and U. Ott, " $P$ value interpretations and considerations," Journal of Thoracic Disease, vol. 8, no. 9, pp. E928-E931, 2016.

[22] C. O. Fritz, P. E. Morris, and J. J. Richler, "Effect size estimates: current use, calculations, and interpretation," Journal of Experimental Psychology: General, vol. 141, no. 1, pp. 2-18, 2012.

[23] H.-Y. Kim, "Statistical notes for clinical researchers: chisquared test and Fisher's exact test," Restorative Dentistry \& Endodontics, vol. 42, no. 2, pp. 152-155, 2017.

[24] P. A. Lachenbruch and J. Cohen, "Statistical power analysis for the behavioral sciences (2nd ed.)," Journal of the American Statistical Association, vol. 84, no. 408, p. 1096, 1989.

[25] A. A. D. Albashir, "The potential impacts of obesity on COVID-19," Clinical medicine (London, England). NLM (Medline), vol. 20, no. 4, pp. e109-e113, 2020.

[26] F. Sanchis-Gomar, C. J. Lavie, M. R. Mehra, B. M. Henry, and G. Lippi, "Obesity and outcomes in COVID-19: when an epidemic and pandemic collide," Mayo Clinic Proceedings, vol. 95, no. 7, pp. 1445-1453, 2020.

[27] A. M. Rychter, A. Zawada, A. E. Ratajczak, A. Dobrowolska, and I. Krela-Kaźmierczak, "Should patients with obesity be more afraid of COVID-19?" Obesity Reviews, vol. 21, no. 9, 2020.

[28] J. Kim and J.-H. Nam, "Insight into the relationship between obesity-induced low-level chronic inflammation and COVID19 infection," International Journal of Obesity, vol. 44, no. 7, pp. 1541-1542, 2020.

[29] M. Deng, Y. Qi, L. Deng et al., "Obesity as a potential predictor of disease severity in young COVID-19 patients: a retrospective study," Obesity, vol. 28, no. 10, pp. 1815-1825, 2020.

[30] D. A. Kass, P. Duggal, and O. Cingolani, "Obesity could shift severe COVID-19 disease to younger ages," The Lancet, vol. 395, no. 10236, pp. 1544-1545, 2020.

[31] P. Zhou, X.-L. Yang, X.-G. Wang et al., “A pneumonia outbreak associated with a new coronavirus of probable bat origin," Nature, vol. 579, no. 7798, pp. 270-273, 2020.

[32] A. A. T. Naqvi, K. Fatima, T. Mohammad et al., "Insights into SARS-CoV-2 genome, structure, evolution, pathogenesis and therapies: structural genomics approach," Biochimica et Biophysica Acta (BBA) - Molecular Basis of Disease, vol. 1866, no. 10 , p. $165878,2020$.

[33] A. B. Engin, E. D. Engin, and A. Engin, "Two important controversial risk factors in SARS-CoV-2 infection: obesity and smoking," Environmental Toxicology and Pharmacology, vol. 78, p. 103411, 2020.

[34] I. Dugail, E. Z. Amri, and N. Vitale, "High prevalence for obesity in severe COVID-19: possible links and perspectives towards patient stratification," Biochimie, vol. 179, pp. 257265, 2020.

[35] S. Al-Benna, "Association of high level gene expression of ACE2 in adipose tissue with mortality of COVID-19 infection in obese patients," Obesity Medicine, vol. 19, p. 100283, 2020.

[36] X. Jia, C. Yin, S. Lu et al., "Two things about COVID-19 might need attention," Preprints, vol. 2, 2020.
[37] R. Kassir, "Risk of COVID-19 for patients with obesity," Obesity Reviews, vol. 21, no. 6, p. e13034, 2020.

[38] Y. Zhang, K. R. Somers, C. Becari et al., "Comparative expression of renin-angiotensin pathway proteins in visceral versus subcutaneous fat," Frontiers in Physiology, vol. 9, p. 1370, 2018.

[39] A. Petersen, K. Bressem, J. Albrecht et al., "The role of visceral adiposity in the severity of COVID-19: highlights from a unicenter cross-sectional pilot study in Germany," Metabolism, vol. 110, 2020.

[40] M. J. West-Eberhard, "Nutrition, the visceral immune system, and the evolutionary origins of pathogenic obesity," Proceedings of the National Academy of Sciences, vol. 116, no. 3, pp. 723-731, 2019.

[41] A. E. Newell-Fugate, "The role of sex steroids in white adipose tissue adipocyte function," Reproduction, vol. 153, no. 4, pp. R133-R149, 2017.

[42] N. Chanana, T. Palmo, K. Sharma, R. Kumar, B. B. Graham, and Q. Pasha, "Sex-derived attributes contributing to SARSCoV-2 mortality," American Journal of Physiology-Endocrinology and Metabolism, vol. 319, no. 3, 2020.

[43] G. Grandi, F. Facchinetti, and J. Bitzer, "The gendered impact of coronavirus disease (COVID-19): do estrogens play a role?" The European Journal of Contraception \& Reproductive Health Care, vol. 25, no. 3, pp. 233-234, 2020.

[44] L. Busetto, S. Bettini, R. Fabris et al., "Obesity and COVID-19: an Italian snapshot," Obesity, vol. 28, no. 9, pp. 1600-1605, 2020.

[45] S. W. X. Ong, B. E. Young, Y. S. Leo, and D. C. Lye, "Association of higher body mass index (BMI) with severe coronavirus disease 2019 (COVID-19) in younger patients," Clinical Infectious Diseases, vol. 71, no. 16, pp. 2300-2302, 2020. 